\title{
Résultats de la votation générale de la coopérative FMH Services
}

\section{Beat Bumbachera, Markus Lehmann ${ }^{b}$}

${ }^{a}$ Dr méd., MLaw, président du conseil d'administration de FMH Services société coopérative; ${ }^{b}$ Directeur de FMH Services société coopérative

Chers Sociétaires,

Par le rapport de gestion, nous vous avons informés en mai 2021 des activités opérationnelles et nous avons soumis à votre approbation le rapport de gestion 2020, l'affectation du résultat ainsi que la décharge au conseil d'administration de FMH Services. En outre, l'élection de Madame le Docteur Regula Friedli-Kronenberg comme nouveau membre du conseil d'administration était en suspens.

Nous nous réjouissons de vous annoncer les résultats de la votation générale et nous vous remercions de votre participation nombreuse et de votre intérêt.

Veuillez agréer, chers Sociétaires, nos salutations les meilleures.

FMH Services société coopérative

\section{Votation générale 2021}

\section{Remise des bulletins de vote}

Du 12 mai au 29 juin 2021 par écrit auprès de la

commune d'Oberkirch

\section{Dépouillement}

M. J. R. Rogger, commune d'Oberkirch

\section{Résultats}

3.1 Proposition $\mathrm{n}^{\circ} 1$

Acceptez-vous le rapport de gestion 2020 de FMH Services?

\begin{tabular}{lr}
\hline Bulletins de vote reçus & 4941 \\
\hline Bulletins invalides (sans signature) & 7 \\
\hline Bulletins vides ou pas de bulletin & 76 \\
\hline Bulletins valables & 4858 \\
\hline Oui & 4775 \\
\hline Non & 83 \\
\hline
\end{tabular}

La proposition $n^{\circ} 1$ est ainsi approuvée à une large majorité.

\subsection{Proposition $n^{\circ} 2$}

Êtes-vous d'accord de reporter le déficit de CHF 83351.02 sur l'exercice suivant et de le déduire des fonds propres?

\begin{tabular}{lr}
\hline Bulletins de vote reçus & 4939 \\
\hline Bulletins invalides (sans signature) & 7 \\
\hline Bulletins vides ou pas de bulletin & 126 \\
\hline Bulletins valables & 4806 \\
\hline Oui & 4563 \\
\hline Non & 243
\end{tabular}

La proposition $n^{\circ} 2$ est ainsi approuvée à une large majorité.

\subsection{Proposition $\mathbf{n}^{\circ} 3$}

Êtes-vous d'accord de donner décharge au conseil d'administration de la coopérative FMH Services pour l'année de référence 2020 ?

\begin{tabular}{lr}
\hline Bulletins de vote reçus & 4942 \\
\hline Bulletins invalides (sans signature) & 7 \\
\hline Bulletins vides ou pas de bulletin & 103 \\
\hline Bulletins valables & 4832 \\
\hline Oui & 4666 \\
\hline Non & 166 \\
\hline
\end{tabular}

La proposition $n^{\circ} 3$ est ainsi approuvée à une large majorité. 


\subsection{Proposition $n^{\circ} 4$}

Acceptez-vous de nommer comme organe de révision pour un nouveau mandat d'un an la firme Truvag Revisions AG à Sursee?

\begin{tabular}{lr}
\hline Bulletins de vote reçus & 4942 \\
\hline Bulletins invalides (sans signature) & 7 \\
\hline Bulletins vides ou pas de bulletin & 104 \\
\hline Bulletins valables & 4831 \\
\hline Oui & 4735 \\
\hline Non & 96
\end{tabular}

La proposition $n^{\circ} 4$ est ainsi approuvée à une large majorité.

\subsection{Proposition $n^{\circ} 5$}

Acceptez-vous de nommer, pour un nouveau mandat d'un an, l'administration communale d'Oberkirch comme instance tierce neutre pour l'exécution de la votation générale?

\begin{tabular}{lr}
\hline Bulletins de vote reçus & 4943 \\
\hline Bulletins invalides (sans signature) & 7 \\
\hline Bulletins vides ou pas de bulletin & 89 \\
\hline Bulletins valables & 4847 \\
\hline Oui & 4790 \\
\hline Non & 57 \\
\hline
\end{tabular}

La proposition $n^{\circ} 5$ est ainsi approuvée à une large majorité.

\subsection{Proposition $n^{\circ} 6$}

Acceptez-vous d'élire Madame le Docteur Regula FriedliKronenberg comme nouveau membre du conseil d'administration?

\begin{tabular}{lr}
\hline Bulletins de vote reçus & 4941 \\
\hline Bulletins invalides (sans signature) & 7 \\
\hline Bulletins vides ou pas de bulletin & 120 \\
\hline Bulletins valables & 4814 \\
\hline Oui & 4664 \\
\hline Non & 150
\end{tabular}

La proposition $n^{\circ} 6$ est ainsi approuvée à une large majorité.

Le résultat de cette votation générale a été confirmé le 9 juillet 2021 par J. R. Rogger, c/o administration communale d'Oberkirch, comme étant correct et exhaustif.

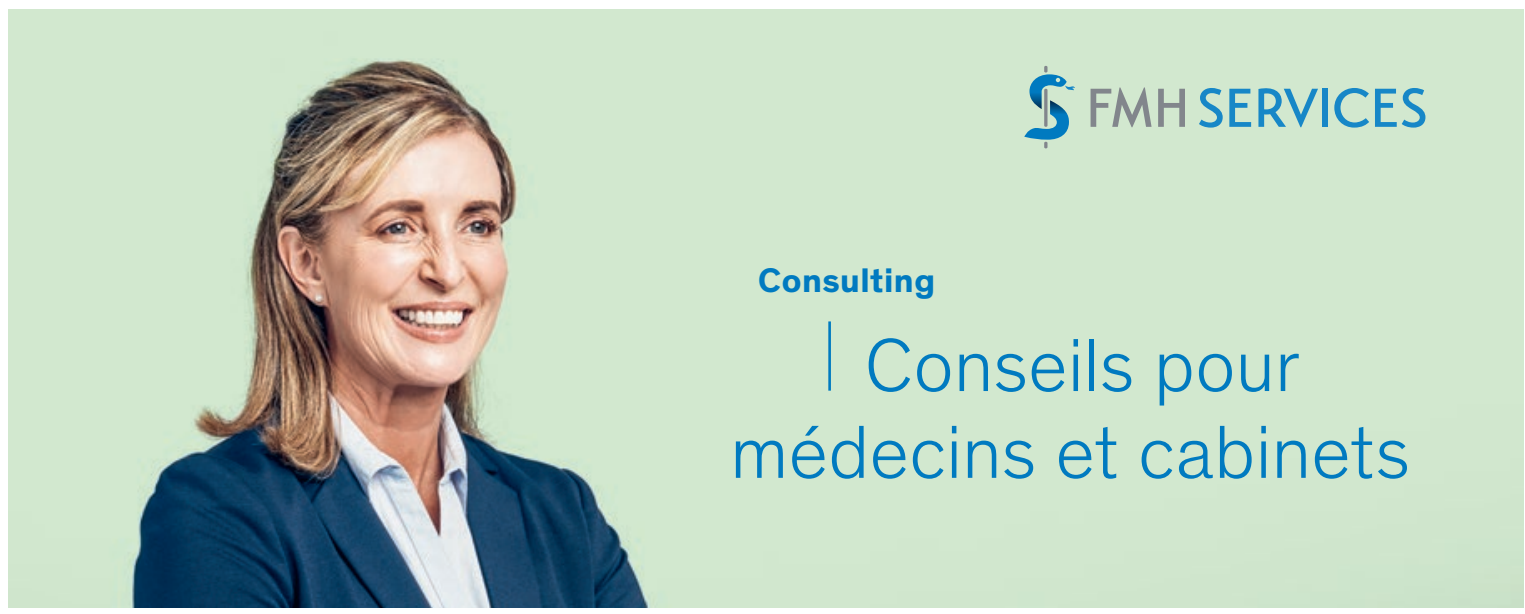

FMH Services est à vos côtés pour toute question d'ordre économique et entrepreneurial.

\section{CONSULTING}

FMH Consulting Services AG

Avenue d'Ouchy 66

1006 Lausanne

Tél. 0219224435

mail@fmhconsulting.ch

www.fmhconsulting.ch 